\title{
Stable hydrogen isotope measurements of songbird feathers: effects of intra-feather variability and sample processing
}

Oscar Gordo

Dept. Conservation Biology, Doñana Biological Station (EBD-CSIC). Américo Vespucio 26, 41092 Sevilla. Spain.

e-mail: ogvilloslada@gmail.com

ORCID: 0000-0003-3766-0566

\begin{abstract}
Deuterium composition of feathers has been widely applied to establish provenance of birds. Surprisingly, little attention has been paid to the potential sources of unwanted hydrogen isotopic variability that may affect the comparability and replicability of deuterium measurements. Feathers may exhibit hydrogen isotopic differences between distal and proximal sections, as well as between rachis and vane. For this reason, it is recommended to always analyse ground vane from the same section of the feather. However, this protocol may be seriously limiting when working with songbird feathers, which are usually small and light. In this paper, intrafeather hydrogen isotopic variability was studied in four species of songbirds by comparing four sections of the same feather. No difference in hydrogen isotopic composition was found between distal and proximal sections of the vane. This was expected as songbird feathers grow rapidly and individuals avoid geographical movements during moult, favouring a homogeneous source of hydrogen during keratin synthesis. Conversely, as previously demonstrated for other avian species, rachis showed systematically c. $11 \%$ o $\delta^{2} \mathrm{H}$ more negative values than vane. This is probably a result of their biochemical and ultrastructural differences, which seem strongly conserved across taxa. Such differences imply that we need to describe which feather part was used in the methods of our reports to ensure full comparability and replicability among studies. Nevertheless, vane and rachis $\delta^{2} \mathrm{H}$ were strongly correlated, demonstrating that rachis can be also used in isotope analyses because its $\delta^{2} \mathrm{H}$ can be accurately rescaled. This is useful since rachis represents an important fraction of feather mass in songbirds. Values of $\delta^{2} \mathrm{H}$ from ground and non-ground samples from the same feather were also compared. There was no effect of the processing protocol, suggesting that grinding is unnecessary when working with passerine feathers.
\end{abstract}

Keywords deuterium, keratinous material, methodology, passerines, protocol, tissue. 


\section{Introduction}

The study of stable isotopes has become a popular tool in trophic and movement ecology research (Hobson 1999; Rubenstein and Hobson 2004; Bowen et al. 2005; Hobson 2011; MeierAugenstein et al. 2013). In birds, stable isotopes measurements have been successfully used to trace the origin of migrants (Dunn et al. 2006; Cárdenas-Ortiz et al. 2017), establish the connectivity between breeding and non-breeding populations of migratory species (Chamberlain et al. 1997; Hobson \& Wassenaar 1997; Marra et al. 1998), unravel the diet of species difficult to track (Procházka et al. 2010; Robillard et al. 2017), discover historical changes in food webs (Emslie and Patterson 2007; Blight et al. 2015), and determine nutrient allocation during reproduction (Klaassen et al. 2001; Jaatinen et al. 2017). Therefore, by selecting suitable element(s), tissue(s) and sampling period(s) within the life cycle, stable isotope research can solve a broad range of essential questions in bird ecology.

Feathers have been regularly used in stable isotope research due to a number of advantages (Smith et al. 2003; Bortolotti 2010). They are replaced regularly and moult strategies are usually known (e.g., Jenni and Winkler 2011), thus becoming an excellent tissue to have a snapshot of the isotope composition of the consumed diet, occupied habitat and geographical location. Furthermore, they are easy to collect and store (McDonald \& Griffith 2011), and by being inert they maintain the chemical signature of the environment where they grew (Wassenaar 2019). In addition, feathers can also be used as a source of DNA, hormones, and to quantify colouration (Katzner et al. 2012), providing further information of the studied individuals, thus improving our understanding of ecological and evolutionary processes of interest.

In spite of the widespread application of feather stable hydrogen isotope analyses, little research has been published on the methodological aspects of its measurement (Wassenaar and Hobson 2006; Smith et al. 2008, 2009; Paritte and Kelly 2009; Wiley et al. 2010; Bontempo et al. 2014; Soto et al. 2017; Wassenaar 2019). This is surprising given the lack of a unified approach to collect and prepare feathers for posterior isotope-ratio mass spectrometry (but see Wassenaar 2019). This heterogeneity in methodologies may affect replicability and comparability among studies (Jardine and Cunjak 2005; Lott and Smith 2006; Wassenaar and Hobson 2006; Paritte and Kelly 2009; Qi and Coplen 2011; Meier-Augenstein et al. 2013; Bontempo et al. 2014).

Feathers are not a homogenous tissue and thus, some intra-feather variability in deuterium composition should be expected. For this reason, the section of the feather selected for the analysis can affect the comparability of deuterium measurements between samples. Feathers are composed of a vane and rachis, which have different ultrastructure and density that can affect isotope deposition (Bortolotti 2010; Grecian et al. 2015). In fact, previous studies demonstrated that rachis normally is more depleted and variable in deuterium than vane (Wassenaar and Hobson 2006; Bontempo et al. 2014). For this reason, it is recommended to exclude rachis from analyses. In addition, some deuterium variability has been observed between the distal and proximal sections of feathers (Wassenaar and Hobson 2006; Smith et al. 2008, 2009; Wiley et al. 2010; Bontempo et al. 2014; Wassenaar 2019), suggesting changes in the source of hydrogen used to synthesize keratin during feather growth. To avoid this problem, one should always select the same section of the feather (Kelly et al. 2002; Smith and Dufty 2005; Pérez and Hobson 2006; Smith et al. 2008, 2009).

Elimination of the rachis and selection of a small vane section are feasible approaches in large birds, in which rachis and vane are patently different and a stamp-size piece of vane may provide several $\mathrm{mg}$ of material, which is enough for several analyses (e.g., several elements and/or replicates). However, in many songbirds, even full flight feathers may be really tiny and light ( $<3 \mathrm{mg}$ ). From such feathers, once the rachis is removed, we might barely obtain $1 \mathrm{mg}$ of 
keratinous material. One $\mathrm{mg}$ is a quite limiting amount of sample, as each isotopic analysis needs around $0.3 \mathrm{mg}$. This challenge has not limited the application of hydrogen stable isotopes research on songbirds (e.g., Chamberlain et al. 1997; Marra et al. 1998; Pérez and Hobson 2006). Nevertheless, intra-feather isotope variability in this group should be properly described in order to elucidate whether or not protocol recommendations cited previously can be flexible and consequently, different sections of the same feather can be used without risk of getting biased results. This issue seems especially relevant, since the vast majority of studies to date about intra-feather isotope variability focused on flight feathers of non-passerines (Wassenaar and Hobson 2006; Smith et al. 2008, 2009; Wiley et al. 2010; Bontempo et al. 2014; Grecian et al. 2015).

Another step during feather processing can be to grind the samples to powder. Reference keratinous materials for the analysis are powdered, thus samples in the same state would ensure full comparability (principle of identical treatment; Chesson et al. 2009; Wassenaar 2019). In fact, tests with mammal hair have demonstrated some effects of particle size on the final measured deuterium abundance (Chesson et al. 2009; Qi and Coplen 2011). Apparently, powdered vs. non-powdered materials would have different hygroscopic properties that affect their capacity to retain residual moisture content, thus having an effect on the exchangeable fraction of hydrogen (Chesson et al. 2009; Qi and Coplen 2011). Surprisingly, no similar tests have been carried out with feathers, therefore it is unknown to what extent the findings with mammal hair are generalizable to other keratinous materials. To challenge the principle of identical treatment in this particular step of the protocol seems especially useful when working with songbird feathers, which are usually small. In this case, grinding can be a serious issue because a fraction of the sample is unavoidably lost during the process (e.g., small barbules adhered on the manipulation tools by static electricity). Therefore, it would be necessary to investigate whether or not entire (small) pieces of feather provide unbiased measurements of deuterium composition.

The aim of this study was to explore the effects of intra-feather hydrogen isotopic variability and sample processing on deuterium abundance measured in songbirds' feathers. The specific objectives were: $i$ ) To study hydrogen isotopic gradients along the feather by comparing samples from the more distal and proximal parts of the same feather. I predicted there would be no deuterium differences, as songbird feathers grow quickly and individuals avoid large displacements during moulting. ii) To study the effect of feather ultrastructure on deuterium composition by comparing sections of rachis and vane from the same feather. In this case, I predicted subtle, but quantifiable deuterium differences between sections. iii) To test the effect of two different protocols of feather processing by analysing ground and non-ground sections from the same feather. I expected an effect of grinding on deuterium measurements, since the exchangeable fraction of hydrogen is affected by particle size, as it has been demonstrated in hair.

\section{Methods}

The feathers $(n=35$ ) were collected from four species (chaffinch Fringilla coelebs, $n=5$; grasshopper warbler Locustella naevia, $n=4$; bluethroat Luscinia svecica, $n=4$; song thrush Turdus philomelos, $n=22$ ) trapped during the autumn migration of 2017 in the Manecorro ringing station located in the Doñana National Park (SW Spain; Arroyo 2004). The sixth secondary was plucked from the right wing of birds. Samples were stored in paper envelopes until their analysis.

Feather calamus was removed because this section of the shaft contains skin and blood residues, which may bias deuterium measurement of feather keratin (Hobson et al. 1999; 
Mazerolle and Hobson 2005; Wolf et al. 2012). Each feather was placed into a small tube and rinsed three times with absolute ethanol and a fourth time with distilled water. For each rinse, washing was enhanced by vortexing for 10 seconds. Wet samples were placed into a drying chamber at $50{ }^{\circ} \mathrm{C}$ during $48 \mathrm{~h}$.

Each feather was divided into four subsamples (Fig. 1). First, the left section of the vane ('vane') was separated with surgical scissors and ground to a homogeneous powder. Therefore, 'vane' provided deuterium composition representative for the full feather's vane in powder form. From the remaining sample of the feather the 'tip', 'bottom' and 'rachis' (Fig. 1) were cut with a scalpel. 'Tip' and 'bottom' aimed to represent the distal and proximal sections of the vane, respectively. Their comparison determined possible isotopic gradients along the feather (objective 1). Irrespective of the existence of such gradients, the 'vane' had to have an average composition of deuterium between 'tip' and 'bottom', otherwise any deviation would imply an effect of the processing protocol (objective 3). It is necessary to clarify that 'tip' included the upper section of the rachis. At the distal region of small feathers these two structures showed similar thickness and consistency making difficult its separation. Finally, 'rachis' was the rachis section contiguous to 'bottom'. Here, rachis was thick and patently different from vane, even in the smallest feathers of the grasshopper warbler. The comparison between 'rachis' and 'bottom' tested the second objective.

An average of $0.303 \mathrm{mg}(0.024 \mathrm{SD})$ of feather from each section was weighed with an electronic microbalance (Sartorius ${ }^{\circledR}$ Cubis Microbalance, $\pm 0.001 \mathrm{mg}$ ) and placed into $5.0 \times 3.3$ $\mathrm{mm}$ silver foil cups (Lüdiswiss, Switzerland) and folded. Encapsulated samples ( $n=140)$ were stored in 96-well plates during one month to ensure equilibrium of the exchangeable hydrogen fraction with ambient water vapour (Wassenaar and Hobson 2003). Samples were analysed in a random order.

Isotope measurements were performed on hydrogen derived from high-temperature flash pyrolysis at $1450{ }^{\circ} \mathrm{C}$ by means of Flash HT Plus elemental analyser coupled to a Delta-V Advantage isotope ratio mass spectrometer via a CONFLO IV interface (Thermo Fisher Scientific, Bremen, Germany). Four keratin reference materials with a known deuterium isotopic composition of the non-exchangeable hydrogen component were used to calibrate results to the Vienna Standard Mean Ocean Water. The reference materials were: CBS (caribou hoof standard, $-157.0 \%$ ), KHS (kudu horn standard, $-35.3 \%$; both supplied by Environment Canada), USGS-42 (human hair from Tibet, -72.2\%; supplied by the Reston Stable Isotope Laboratory) and LIE-PA2 (an internal standard made from razorbill feather, $+3.8 \%$ ). Reference materials were encapsulated following the same protocol described previously and simultaneously to feather samples. Samples and reference materials were stored together for hydrogen equilibration (Wassenaar and Hobson 2003; Wassenaar 2019).

The isotopic composition is reported in the conventional delta $\left(\delta^{2} H\right)$ per mil notation (\%o). Replicate assays of laboratory standards routinely inserted within the sampling sequence indicated analytical measurement errors of $\pm 1.6 \%$ (SD, $n=1023$ ).

Feather processing and isotopic analyses were performed at the Stable Isotope Lab of the Estación Biológica de Doñana (Spain), which is certified to ISO9001:2015 and ISO14001:2015 quality and environmental management systems.

I used repeated measures ANOVA to test for differences between the four studied sections of the feather. The species was included as a categorical predictor. Greenhouse-Geisser $(\hat{\varepsilon})$ and the Huynh-Feldt $(\tilde{\varepsilon})$ estimations of sphericity of the variance-covariance matrix (Greenhouse and Geisser 1959; Huynh and Feldt 1976) were used to correct the degrees of freedom of the model. I applied Bonferroni post hoc tests to determine statistical differences between feather sections (Maxwell 1980). To obtain conversion formulae, I fitted linear 
regression models between pairs of feather sections that were statistically different in the previous post hoc test. All analyses were conducted with Statistica 7.0 (StatSoft, Inc).

\section{Results}

There were statistically significant differences among the $\delta^{2} \mathrm{H}$ in each section of the feather (Table 1). 'Rachis' had $\delta^{2} \mathrm{H}$ values around $11 \%$ lower than 'vane' and 'bottom', and around $8 \%$ lower than 'tip' (Fig. 2). Interestingly, 'tip' also differed significantly from 'vane' and 'bottom' (Bonferroni post hoc test $p<0.001$ ) showing, in general, more negative $\delta^{2} \mathrm{H}$ values (Fig. 2). The $\delta^{2} \mathrm{H}$ values for all feather sections differed consistently in all species but the grasshopper warbler (Fig. 2; Table 1). Moreover, as 'vane' and 'bottom' had the same $\delta^{2} \mathrm{H}$, the hypothesis of deuterium gradients along the feather was rejected, as well as, any potential effects of vane grinding.

In spite of the differences, $\delta^{2} \mathrm{H}$ values between different sections of the feather were strongly correlated (Table 2). Thus, variability among individuals was captured in the same way by any feather section.

\section{Discussion}

The most important intra-feather variation in deuterium composition in passerine feathers was between rachis and vane, a difference already noticed in several non-passerine species (Wassenaar and Hobson 2006; Wiley et al. 2010; Bontempo et al. 2014). Such difference between rachis and vane was expected because they have biochemical and structural differences (Harrap and Woods 1967; King and Murphy 1987), which may affect hydrogen isotope incorporation (Bortolotti 2010; Grecian et al. 2015) and exchange (Meier-Augenstein et al. 2013). The magnitude of the observed differences in $8^{2} \mathrm{H}$ (c. $11 \%$ ) was similar to the $6.8 \%$ (2.6\% SD) found previously for the Swainson's thrush (Catharus ustulatus; Wassenaar and Hobson 2006). Although the number of analysed samples for the grasshopper warbler, the chaffinch and the bluethroat was small, this $11 \%$ difference between rachis and vane was surprisingly constant among individuals and species. Overall, this finding, as well as that by Wassenaar and Hobson (2006), suggests strong similarities among passerines in the biochemical processes controlling hydrogen isotope composition in feathers, regardless of their phenotypic characters, such as size, shape and colour (but see Michalik et al 2010). This hypothesis concurs with the fact that differences in amino acid composition between rachis and vane are larger within than between species (Schroeder et al. 1955; Harrap and Woods 1967; King and Murphy 1987), suggesting a strong evolutionary conservation of feather keratins (Murphy et al. 1990). As amino acid composition of proteins affects the hydrogen exchangeable fraction (MeierAugenstein et al. 2013), the slight differences in the amino acid composition between rachis and vane seem the most plausible underlying cause for their $\delta^{2} \mathrm{H}$ differences. Nevertheless, a more extensive sample of species would be necessary to confirm that hydrogen isotopic differences between rachis and vane are conserved across all passerine taxa. In the same way, a similar study for other elements used regularly in isotope research, such as $\mathrm{C}$ or $\mathrm{N}$, would be advisable too (but see Bontempo et al. 2014; Grecian et al. 2015).

The observed $\delta^{2} \mathrm{H}$ differences between vane and rachis require special attention. In fact, both parts should be considered to some extent as different tissues, since they present a different factor of hydrogen isotope discrimination (Wolf et al. 2012; Grecian et al. 2015), making impossible a direct comparison of their results. For instance, if the tip of a small feather is clipped and it is necessary to use the whole piece in the isotope analysis, the $\delta^{2} \mathrm{H}$ will be around $3 \%$ lower than expected in a pure vane sample. In consequence, the measured $\delta^{2} \mathrm{H}$ will bias $\mathrm{c}$. 
$350 \mathrm{~km}$ of latitude the assignment of the provenance of the bird. Therefore, it seems essential to state explicitly in the methodology of our studies, whether or not rachis was included. Surprisingly, this information is usually not reported, hindering the comparability and replicability of the studies (Meier-Augenstein et al. 2013). Since most ecologists rely on specialists to carry out their laboratory analyses, they can be underestimating or even ignoring these potential issues (Jardine and Cunjak 2005; Hawke et al. 2018).

Due to the hydrogen isotopic differences between rachis and vane, some authors recommend to use only vane as a source of keratinous material for deuterium analyses (Wassenaar and Hobson 2006; Bontempo et al. 2014; but see Meehan et al. 2003). However, in some instances this is not possible. Samples may be limited to small feathers, such as contour feathers, since they might be the only ones that moulted during the life cycle period of our interest (Chamberlain et al. 1997; Kelly et al. 2002; Mazerolle and Hobson 2006; Hobson 2007; Langin et al. 2007; Rader et al. 2017) or the only ones allowed to be collected in museum specimens (Smith et al. 2009; Wiley et al. 2017). In other cases, because of ethical reasons feather samples can be limited to a clipped piece of few millimetres (Pérez and Hobson 2006; McDonald and Griffith 2011). Since passerine feathers are light structures, small samples, as those previously cited, can seriously restrict the possibilities to obtain deuterium measurements due to insufficient vane mass. Moreover, analyses for other isotopes or replicates would be unfeasible, limiting our ability to get the maximum information per sample. In these situations, a flexible protocol allowing to include the rachis in the analysis can be helpful since the rachis represents a relevant fraction of the total feather mass (King and Murphy 1987; Murphy et al. 1990). For instance, in this study, the feathers weighed between 3 and $5 \mathrm{mg}$ and the rachis represented c. 50\% of their weight. As demonstrated here, $\delta^{2} \mathrm{H}$ values from rachis were strongly correlated to those values from vane. This property grants the possibility to apply linear transformations to the results to get unbiased deuterium measurements in samples containing rachis.

Contrary to previous work (Wassenaar and Hobson 2006; Smith et al. 2008, 2009; Wiley et al. 2010; Bontempo et al. 2014; Grecian et al. 2015; Wassenaar 2019), feathers did not show isotopic gradients between bottom and tip. This opposite result can be due to the fact that I worked with passerines, while this type of intra-feather variation has been found in nonpasserines. In species, such as raptors (Smith et al. 2008, 2009) or herons (Wassenaar and Hobson 2006), full replacement of a single flight feather takes between 7 and 14 weeks (Mehaan et al. 2003; Zuberogoitia et al. 2018). During this period, individuals may move long distances (e.g., migration) and their feathers may incorporate along their length all this environmental variability. However, in passerines, single feathers are replaced in few days (Newton 1967; Bensch et al. 1991; De la Hera et al. 2011). Furthermore, passerines during moult do not move long distances because of the energy demands of the moulting process and their impaired flying abilities (Mërila 1997; Swaddle and Witter 1997). Thus, in passerines, a feather grows completely at the same place during a short time period. In consequence, feathers would use a homogeneous source of hydrogen, which would favour a homogeneous deuterium composition along their entire length. Therefore, by resampling different sections of the vane, e.g. to repeat analyses, $\delta^{2} \mathrm{H}$ measurements are not affected. This finding is also useful when the available section of the feather varies between individuals, as when the target feather is broken.

In opposition to mammal hair (Chesson et al. 2009; Qi and Coplen 2011), grinding did not have any effect on $\delta^{2} \mathrm{H}$ measures in feather samples. Probably, grinding does not have a critical effect on hydrogen exchange between feather materials and ambient humidity due to the natural structure of the vane. By grinding this complex structure of barbs and barbules up to small particles, one obtains a similar material than by cutting a small vane piece of a few millimetres. Therefore, in spite of the fact that we would be violating the principle of identical treatment (Wassenaar and Hobson 2003; Chesson et al. 2009; Wassenaar 2019), empirical 
evidence suggests that we may be somewhat flexible in the grinding step of the protocol. Grinding might be recommended when there is evidence of intra-feather heterogeneity (Wassenaar and Hobson 2006; Smith et al. 2008; Wiley et al. 2010). Under these circumstances, tissue homogenization can provide a more integrative value for the full feather enhancing any comparison between samples (Smith et al. 2009; Wiley et al. 2018). However, when there is no intra-vane heterogeneity, as in the case of passerine feathers, grinding should be discouraged. Grinding is a destructive technique (Wiley et al. 2010) and remaining sections of feathers will not be available for other purposes, such as colour, ptilocronological, and biomechanical studies (Senar 2004; De la Hera 2010). Grinding also requires more working time by adding an extra step in the feather processing protocol. Finally, perhaps the main drawback of grinding is that part of the sample is unavoidably lost in the process (e.g., adhered on grinding tools). This fact can be a serious difficulty when working with small passerine feathers, in which the amount of keratinous material can be somewhat limiting.

In conclusion, working with passerine feathers may be arduous because of the limited amount of sample that they provide. This study demonstrates that protocols can be flexible to some extent because: 1 ) any section of the vane can be used since there are no hydrogen isotopic differences along the feather; 2 ) the rachis can be included despite its lower $\delta^{2} \mathrm{H}$, since conversion equations can be applied to get unbiased results; 3 ) grinding can be avoided, since particle size does not have any effects on the exchangeable hydrogen fraction in feather material. This flexibility in the processing protocol can help to maximize the information obtained from passerine feathers.

Acknowledgments I thank to José Luis Arroyo, Rubén Rodríguez, Ángel Sallent and Benito Fuertes for collecting samples, and Sarai López and Manuela G. Forero for their assistance in the lab. I am especially grateful to Margarida Barceló-Serra for her manuscript review and English edits. Two anonymous reviewers provided helpful comments that improved a first version of this article. Feather sampling was conducted in accordance with Spanish law, approved by the Ethical Committee of the CSIC (ref. 23/02/2018/015), and with the permits given by the Dirección General de Gestión del Medio Natural y Espacios Protegidos de la Junta de Andalucía, and the Espacio Natural de Doñana (no. 2017/20). OG also has a training certificate (no. 000023) given by the IFAPA (Junta de Andalucía) which, according to Spanish Law (ECC/566/2015), is necessary for any experiments with animals. This study was funded by a grant to OG from the Spanish Ministry of Economy (ref. CGL2014-56041-JIN).

\section{References}

Arroyo JL (2004) La estación de anillamiento de Manecorro (Parque Nacional de Doñana, Huelva): anillamiento de paseriformes durante la migración postpnucial (1994-2005). Revista de Anillamiento 13:56-66

Bensch S, Hasselquist D, Hedenström A, Ottosson U (1991) Rapid moult among palaearctic passerines in West Africa-an adaptation to the oncoming dry season? Ibis 133:47-52

Blight LK, Hobson KA, Kyser TK, Arcese P (2015) Changing gull diet in a changing world: A 150-year stable isotope $\left(\delta^{13} \mathrm{C}, \delta^{15} \mathrm{~N}\right)$ record from feathers collected in the Pacific Northwest of North America. Global Change Biol 21:1497-1507

Bontempo L, Ceppa F, Ziller L, Pedrini P, Hobson KA, Wassenaar LI, Camin F (2014) Comparison of methods for stable isotope ratio $\left(\delta^{13} \mathrm{C}, \delta^{15} \mathrm{~N}, \delta^{2} \mathrm{H}, \delta^{18} \mathrm{O}\right)$ measurements of feathers. Method Ecol Evol 5:363-371

Bortolotti GR (2010) Flaws and pitfalls in the chemical analysis of feathers: bad news-good news for avian chemoecology and toxicology. Ecol Appl 20:1766-1774

Bowen GJ, Wassenaar LI, Hobson KA (2005) Global application of stable hydrogen and oxygen isotopes to wildlife forensics. Oecologia 143:337-348

Cárdenas-Ortiz L, Bayly NJ, Colorado ZGJ, Hobson KA (2017) Fall migration and breeding origins of Canada Warblers moving through northern Colombia. J Field Ornithol 88:53-64

Chamberlain CP, Blum JD, Holmes RT, Feng X, Sherry TW, Graves GR (1996) The use of isotope tracers for identifying populations of migratory birds. Oecologia 109:132-141

Chesson LA, Podlesak DW, Cerling TE, Ehleringer JR (2009) Evaluating uncertainty in the calculation of nonexchangeable hydrogen fractions within organic materials. Rapid Comm Mss Spec 23:1275-1280 
De la Hera I, Hedenström A, Pérez-Tris J, Tellería JL (2010) Variation in the mechanical properties of flight feathers of the blackcap Sy/via atricapilla in relation to migration. J Avian Biol 41:342-347

De la Hera I, Schaper SV, Díaz JA, Pérez-Tris J, Bensch S, Tellería JL (2011) How much variation in the molt duration of passerines can be explained by the growth rate of tail feathers? Auk 128:321-329

Dunn E, Hobson K, Wassenaar L, Hussell D, Allen M (2006) Identification of summer origins of songbirds migrating through southern Canada in autumn. Avian Conserv Ecol 1(2):4

Emslie SD, Patterson WP (2007) Abrupt recent shift in $\delta^{13} \mathrm{C}$ and $\delta^{15} \mathrm{~N}$ values in Adélie penguin eggshell in Antarctica. PNAS 104:11666-11669

Grecian WJ, McGill RA, Phillips RA, Ryan PG, Furness RW (2015) Quantifying variation in $\delta^{13} \mathrm{C}$ and $\delta^{15} \mathrm{~N}$ isotopes within and between feathers and individuals: Is one sample enough? Mar Biol 162:733-741

Greenhouse SW, Geisser S (1959) On methods in the analysis of profile data. Psychometrika 24:95-112

Harrap BT, Woods EF (1967) Species differences in the proteins of feathers. Comp Biochem Physiol 20:449-460

Hawke DJ, Brown JC, Bury SJ (2018) The prevention and detection of human error in ecological stable isotope analysis. Methods Ecol Evol 9:2326-2333

Hobson KA (1999) Tracing origins and migration of wildlife using stable isotopes: a review. Oecologia 120:314-326

Hobson KA (2007) An isotopic exploration of the potential of avian tissues to track changes in terrestrial and marine ecosystems. Terr Ecol 1:127-144

Hobson KA (2011) Isotopic ornithology: a perspective. J Ornithol 152:49-66

Hobson KA, Atwell L, Wassenaar LI (1999) Influence of drinking water and diet on the stable-hydrogen isotope ratios of animal tissues. PNAS 96:8003-8006

Hobson KA, Wassenaar LI (1997) Linking breeding and wintering grounds of neotropical migrant songbirds using stable hydrogen isotopic analysis of feathers. Oecologia 109:142-148

Huynh H, Feldt LS (1976) Estimation of the Box correction for degrees of freedom from sample data in randomised block and split-plot designs. J Educ Stat 1:69-82

Jaatinen K, Öst M, Hobson KA (2016) State-dependent capital and income breeding: a novel approach to evaluating individual strategies with stable isotopes. Front Zool 13:24

Jardine TD, Cunjak RA (2005) Analytical error in stable isotope ecology. Oecologia 144:528-533

Jenni L, Winkler R (2011) Moult and ageing of European passerines. Christopher Helm, London

Katzner TE, Wheeler M, Negro JJ, Kapetanakos Y, DeWoody JA, Horvath M, Lovette I (2012) To pluck or not to pluck: scientific methodologies should be carefully chosen, not 'one size fits all'. J Avian Biol 43:15-17

Kelly JF, Atudorei V, Sharp ZD, Finch DM (2002) Insights into Wilson's Warbler migration from analyses of hydrogen stable-isotope ratios. Oecologia 130:216-221

King JR, Murphy ME (1987) Amino acid composition of the calamus, rachis, and barbs of white-crowned sparrow feathers. Condor 89:436-439

Klaassen M, Lindström Å, Meltofte H, Piersma T (2001) Arctic waders are not capital breeders. Nature 413:794

Langin KM, Reudink MW, Marra PP, Norris DR, Kyser TK, Ratcliffe LM (2007) Hydrogen isotopic variation in migratory bird tissues of known origin: implications for geographic assignment. Oecologia 152:449-457

Lott CA, Smith JP (2006) A geographic-information-system approach to estimating the origin of migratory raptors in North America using stable hydrogen isotope ratios in feathers. Auk 123:822-835

Marra PP, Hobson KA, Holmes RT. (1998) Linking winter and summer events in a migratory bird by using stablecarbon isotopes. Science 282:1884-1886

Maxwell SE (1980) Pairwise multiple comparisons in repeated measures designs. J Educ Stat 5:269-287

Mazerolle DF, Hobson KA (2005) Estimating origins of short-distance migrant songbirds in North America: Contrasting inferences from hydrogen isotope measurements of feathers, claws, and blood. Condor 107:280288

McDonald PG, Griffith SC (2011) To pluck or not to pluck: the hidden ethical and scientific costs of relying on feathers as a primary source of DNA. J Avian Biol 42:197-203

Meehan TD, Rosenfield RN, Atudorei VN, Bielefeldt J, Rosenfield L, Stewart AC, Stout WE, Bozek MA (2003) Variation in hydrogen stable-isotope ratios between adult and nestling Cooper's Hawks. Condor 105:567-572

Meier-Augenstein W, Hobson KA, Wassenaar LI (2013) Critique: measuring hydrogen stable isotope abundance of proteins to infer origins of wildlife, food and people. Bioanalysis 5:751-767

Merilä J (1997) Fat reserves and moult-migration overlap in goldcrests, Regulus regulus - A trade-off? Ann Zool Fenn 34:229-234

Michalik A, McGill RA, Furness RW, Eggers T, van Noordwijk HJ, Quillfeldt P (2010) Black and white-does melanin change the bulk carbon and nitrogen isotope values of feathers? Rapid Commun Mass Sp 24:875-878

Murphy ME, King JR, Taruscio TG, Geupel GR (1990) Amino acid composition of feather barbs and rachises in three species of pygoscelid penguins: nutritional implications. Condor 92:913-921

Newton I (1967) Feather growth and moult in some captive finches. Bird Study 14:10-24 
Paritte JM, Kelly JF (2009) Effect of cleaning regime on stable-isotope ratios of feathers in Japanese Quail (Coturnix japonica). Auk 126:165-174

Pérez GE, Hobson KA (2006) Isotopic evaluation of interrupted molt in northern breeding populations of the Loggerhead Shrike. Condor 108:877-886

Procházka P, Reif J, Hořák D, Klvaňa P, Lee RW, Yohannes E (2010) Using stable isotopes to trace resource acquisition and trophic position in four Afrotropical birds with different diets. Ostrich 81:273-275

Qi H, Coplen TB (2011) Investigation of preparation techniques for $\delta^{2} \mathrm{H}$ analysis of keratin materials and a proposed analytical protocol. Rapid Comm Mass Spec 25:2209-2222

Rader JA, Newsome SD, Sabat P, Chesser RT, Dillon ME, Martínez del Rio C (2017) Isotopic niches support the resource breadth hypothesis. J Anim Ecol 86:405-413

Robillard A, Gauthier G, Therrien JF, Fitzgerald G, Provencher JF, Bêty J (2017) Variability in stable isotopes of snowy owl feathers and contribution of marine resources to their winter diet. J Avian Biol 48:759-769

Rubenstein DR, Hobson KA (2004) From birds to butterflies: animal movement patterns and stable isotopes. Trends Ecol Evol 19:256-263

Schroeder WA, Kay LM, Lewis B, Munger N (1955) The amino acid composition of certain morphologically distinct parts of white turkey feathers, and of goose feather barbs and goose down. J Am Chem Soc 77:3901-3908

Senar JC (2004) Mucho más que plumas. Monografies del Museu de Ciències Naturals no 2 . Institut de Cultura de Barcelona - Ajuntament de Barcelona, Barcelona

Smith AD, Donohue K, Dufty Jr AM (2008) Intrafeather and intraindividual variation in the stable-hydrogen isotope $(\delta D)$ content of raptor feathers. Condor 110:500-506

Smith AD, Lott CA, Smith JP, Donohue KC, Wittenberg S, Smith KG, Goodrich L (2009) Deuterium measurements of raptor feathers: Does a lack of reproducibility compromise geographic assignment? Auk 126:41-46

Smith TB, Marra PP, Webster MS, Lovette I, Gibbs HL, Holmes RT, Hobson KA, Rohwer, S. (2003). A call for feather sampling. Auk 120:218-221

Soto DX, Koehler G, Wassenaar LI, Hobson KA (2017) Re-evaluation of the hydrogen stable isotopic composition of keratin calibration standards for wildlife and forensic science applications. Rapid Commun Mass Sp 31:11931203

Speakman JR (2005) The role of technology in the past and future development of the doubly labelled water method. Isot Environ Health S 41:335-343

Swaddle JP, Witter MS (1997) The effects of molt on the flight performance, body mass, and behavior of European starlings (Sturnus vulgaris): an experimental approach. Can J Zool 75:1135-1146

Wassenaar LI (2019) Introduction to conducting stable isotopes measurements for animal migration studies. In: ed Hobson KA \& Wassenaar LI (eds) Tracking animal migration with stable isotopes, 2nd edn. Elsevier, London, pp 25-51

Wassenaar LI, Hobson KA (2003) Comparative equilibration and online technique for determination of nonexchangeable hydrogen of keratins for use in animal migration studies. Isot Environ Health S 39:211-217

Wassenaar LI, Hobson KA (2006) Stable-hydrogen isotope heterogeneity in keratinous materials: mass spectrometry and migratory wildlife tissue subsampling strategies. Rapid Commun Mass Sp 20:2505-2510

Wiley AE, Ostrom PH, Stricker CA, James HF, Gandhi H (2010) Isotopic characterization of flight feathers in two pelagic seabirds: sampling strategies for ecological studies. Condor 112:337-346

Wiley AE, James HF, Ostrom PH (2017) Emerging techniques for isotope studies of avian ecology. In: Webster MS (ed) The extended specimen: Emerging frontiers in collections-based ornithological research. CRC Press, Boca Raton (FL), pp 89-109

Wolf N, Newsome SD, Fogel ML, Martínez del Rio C (2012) An experimental exploration of the incorporation of hydrogen isotopes from dietary sources into avian tissues. J Exp Biol 215:1915-1922

Zuberogoitia I, Zabala J, Martínez JE (2018) Moult in birds of prey: a review of current knowledge and future challenges for research. Ardeola 65:183-208 
Table 1 Results of the repeated measures ANOVA for the $\delta^{2} \mathrm{H}$ measured in each section of the feather. G-G are the results obtained from the adjustment of the Greenhouse-Geiser $\hat{\varepsilon}=0.810$, while H-F are those from the adjustment of Huynh-Feldt $\tilde{\varepsilon}=0.967$.

\begin{tabular}{lrrrrrrrrr}
\hline & & & & & & $\begin{array}{c}\text { G-G } \\
\text { adj. d.f. }\end{array}$ & $\begin{array}{c}\text { G-G } \\
\text { adj. } p\end{array}$ & $\begin{array}{c}H-F \\
\text { adj. d.f. }\end{array}$ & $\begin{array}{c}\text { H.F. } \\
\text { adj. } p\end{array}$ \\
\hline between species & SS & d.f. & MS & $F$ & $p$ & & & & \\
spp & 1406.5 & 3 & 468.8 & 0.388 & 0.763 & & & & \\
Error & 37499 & 31 & 1210 & & & & & & \\
within species & & & & & & & & & \\
Feather section & 1457.0 & 3 & 485.7 & 91.41 & $<0.001$ & 2.429 & $<0.001$ & 2.906 & $<0.001$ \\
Feather section x spp & 91.8 & 9 & 10.20 & 1.920 & 0.058 & 7.288 & 0.075 & 8.718 & 0.061 \\
Error & 494.1 & 93 & 5.30 & & & 75.31 & & 90.08 & \\
\hline
\end{tabular}


Table 2 Conversion equations to rescale $\delta^{2} \mathrm{H}$ values from different sections of a feather.

\begin{tabular}{lccl}
\hline Sections & $r^{2}$ & $p$ & Equation \\
\hline vane vs rachis & 0.9807 & $<0.001$ & vane $=10.19687+1.01084 *$ rachis \\
vane vs tip & 0.9721 & $<0.001$ & vane $=0.23132+0.94339 *$ tip \\
\hline
\end{tabular}


Fig 1 The four subsamples obtained from each feather. See text for details on the procedures applied to each section.

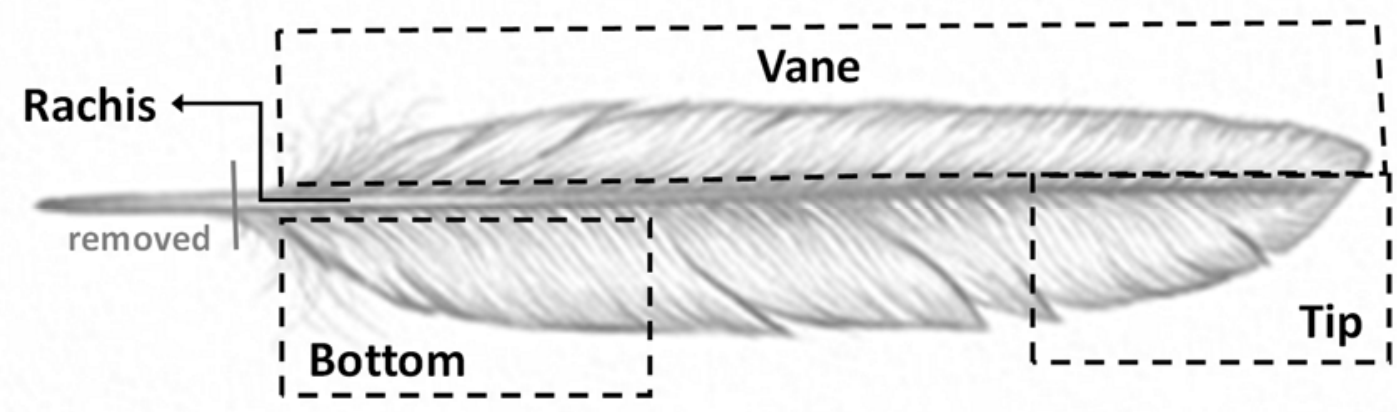


Fig $2 \delta^{2} \mathrm{H}$ for each section of the feather in each studied species. Due to the large differences in the $\delta^{2} \mathrm{H}$ among individuals, $\delta^{2} \mathrm{H}$ values has been rescaled using the mean value of each individual to improve visualization. Therefore, each point shows the average of individuals' deviations in $\delta^{2} \mathrm{H}$. Bars denote the $95 \%$ confidence intervals.

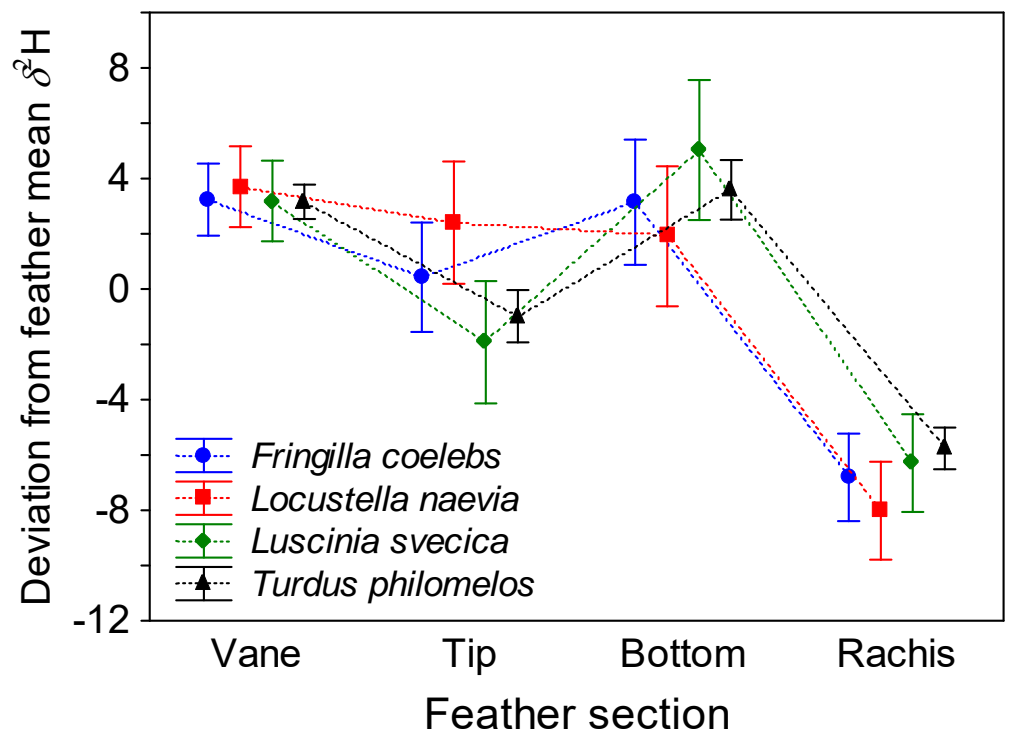

